\title{
periferio
}

\section{A PRODUÇÃO DE POLÍTICAS DE CURRÍCULO PARA GEOGRAFIA NO ESTADO DO RIO DE JANEIRO: SENTIDOS DOCENTES PARA ALÉM DO MÍNIMO}

\author{
Phelipe Florez Rodrigues ${ }^{1}$ \\ Secretaria de Estado de Educação do Rio de Janeiro \\ Hugo Heleno Camilo Costa ${ }^{2}$ \\ Universidade do Estado do Rio de Janeiro - PROPED/UERJ
}

\section{Resumo}

Em 2011, a Secretaria Estadual de Educação do Rio de Janeiro divulgou o currículo mínimo, cujas definições tendem a ser interpretadas como excludentes pelos docentes da rede. Diante das tensões envolvidas nas leituras do documento, focalizamos as críticas docentes à proposta curricular, buscando compreender as negociações tramadas na relação com ela. Apoiamo-nos na abordagem ao ciclo de políticas de Ball, tomando-a como instrumento interpretativo à produção política, com vistas aos processos de recontextualização e tradução performados pelos atores envolvidos. Concluímos que o currículo mínimo de Geografia é, simultaneamente, interpretado pelos professores como antagonismo às práticas que defendem e apropriado contextualmente na produção de novos sentidos na política.

Palavras chave: políticas de currículo; ensino de geografia; currículo mínimo

\footnotetext{
${ }^{1}$ Graduado em Geografia pela Universidade Federal Fluminense (UFF), mestre pelo Programa de Pós-graduação em Educação da Universidade do Estado do Rio de Janeiro (Proped-UERJ). Professor da Seecretaria de Estado de Educação do Rio de Janeiro (SEEDUC-RJ)

2 Mestre em educação pelo PROPED/UERJ e doutorando em educação pelo mesmo programa. Professor substituto da Faculdade de Educação da UERJ. Desenvolve pesquisas na área de currículo, voltando-se para os temas: Políticas de Currículo, Ensino de Geografia, Subjetivação política, Pós-estruturalismo.
} 


\title{
periferio
}

\section{THE PRODUCTION OF CURRICULUM POLICIES FOR GEOGRAPHY IN RIO DE JANEIRO STATE: \\ TEACHER'S SENSES BEYOND THE MINIMUM}

\begin{abstract}
In 2011, the state Department of Education of Rio de Janeiro announced the minimum curriculum, whose settings tend to be interpreted as exclusionary by network teachers. Faced with the tensions involved in the readings of the document, we focus on the criticism of teachers to the curriculum proposal, seeking to understand the plotted negotiations in relation to it. We rely on the approach to the Ball's policy cycle, taking it as an interpretative tool of political production, with a view to recontextualising and translation processes performed by the actors involved. We conclude that the minimum Geography curriculum is simultaneously interpreted by teachers as antagonism to the practices that advocate and contextually appropriated in the production of new meanings in policy.
\end{abstract}

Keywords: curriculum policies; geography teaching; minimum curriculum 


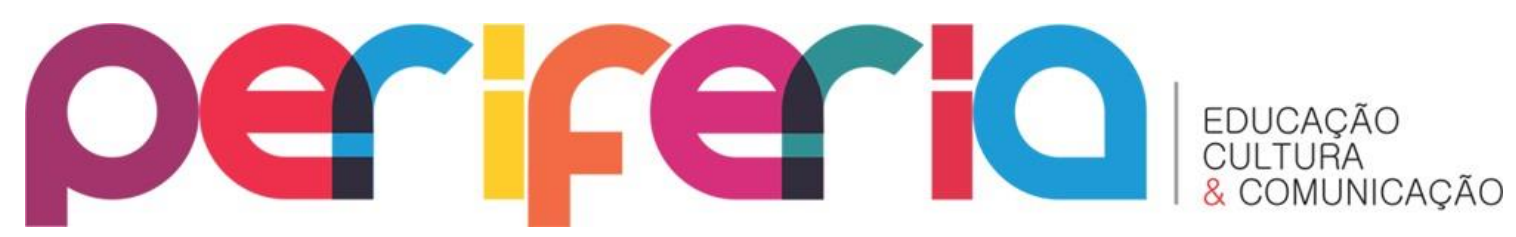

\section{DEFESAS AO MÍNIMO}

Desde 2011 a rede estadual de educação do Rio de Janeiro, tem como uma de suas principais políticas de planejamento a elaboração de um currículo mínimo, cujo objetivo é consolidar uma proposta de orientação aos professores de cada disciplina da escola básica. O currículo mínimo é um documento organizado em um planejamento por anos e bimestres, que contém os conteúdos que devem ser trabalhados ao longo da trajetória escolar do aluno da rede.

Muito focado em um alinhamento do ensino em todo o Estado do Rio de Janeiro, a preocupação em estabelecer e garantir que habilidades e competências sejam desenvolvidas, através de dados conteúdos lidos como mínimos, ao longo do que é denominado como processo de ensinoaprendizagem, é muito forte, sendo reiterada tal perspectiva desde sua introdução, no documento divulgado no ano 2012 (RIO DE JANEIRO, 2012). Em tal texto, o primeiro a estabelecer orientações para todas as disciplinas da escola básica (Matemática, Língua Portuguesa/Literatura, Geografia, História, Sociologia, Filosofia, Ciências /Biologia, Física, Química, Língua Estrangeira, Educação Física e Arte), argumenta-se:

A Secretaria de Estado de Educação do Rio de Janeiro elaborou o Currículo Mínimo da nossa rede de ensino. Este documento serve como referência a todas as nossas escolas, apresentando as competências e habilidades que devem estar nos planos de curso e nas aulas.

Sua finalidade é orientar, de forma clara e objetiva, os itens que não podem faltar no processo de ensino-aprendizagem, em cada disciplina, ano de escolaridade e bimestre. Com isso, pode-se garantir uma essência básica comum a todos e que esteja alinhada com as atuais necessidades de ensino, identificadas não apenas nas legislações vigentes, Diretrizes e Parâmetros Curriculares Nacionais, mas também nas matrizes de referência dos principais exames nacionais e estaduais. "Consideram-se também as compreensões e tendências atuais das teorias científicas de cada área de conhecimento e da Educação e, principalmente, as condições e necessidades reais 


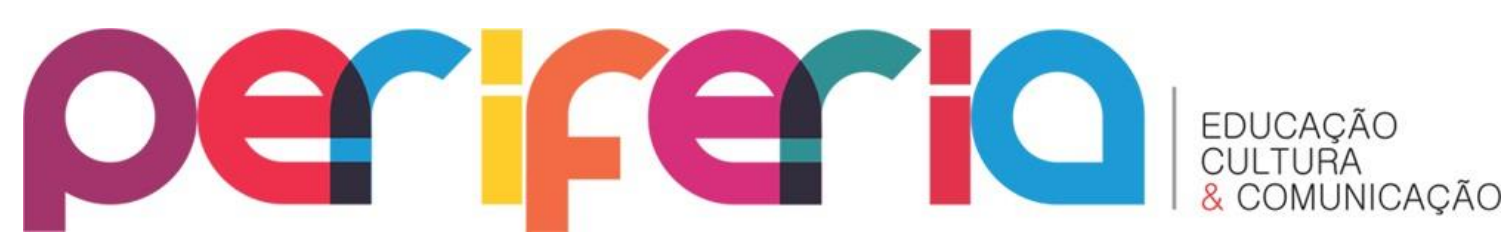

encontradas pelos professores no exercício diário de suas funções. (RIO DE JANEIRO, 2012, p.3)

Ao longo da gestão dos secretários de educação do estado, Wilson Risolia (2007 - 2014) e Antônio Neto (2015 - 2016), tem sido desenvolvidas propostas de valorização do currículo mínimo para o ensino no estado, além de um envolvimento maior da secretaria e das coordenadorias regionais de educação em fiscalizar e garantir que o currículo mínimo seja respeitado e cumprido. Uma marca deste envolvimento é a portaria SEEDUC-RJ3 419/2013, sobre a avaliação de desempenho escolar. Dentre várias determinações normativas, a portaria coloca a obrigatoriedade em utilizar o SAERJINHO 4 como instrumento de avaliação obrigatório na composição da nota bimestral do discente:

Parágrafo $5^{\circ}$ - A avaliação diagnóstica bimestral do processo de ensino aprendizagem - SAERJINHO, aplicada nos níveis de ensino, anos/série, disciplinas e bimestres definidos pela SEEDUC, é um dos instrumentos avaliativos obrigatórios para a composição da nota bimestral do discente, com valor/nota definido (a) pelo professor, e deverá ser registrada no Diário de Classe ou outro instrumento indicado pela SEEDUC, bem como no sistema eletrônico de registro escolar. (RIO DE JANEIRO, 2013).

Esta medida é significada pelos professores ${ }^{5}$ da rede como ainda mais controladora das práticas docentes em relação ao currículo mínimo, levando à redução dos objetivos do ensino da rede aos conteúdos determinados, haja

\footnotetext{
${ }^{3}$ Secretaria de Estado de Educação do Rio de Janeiro.

4 Programa da avaliação diagnóstica do processo de ensino-aprendizagem realizado nas unidades escolares da rede estadual do Rio de Janeiro na escola básica. Trata-se de uma avaliação externa.

${ }^{5}$ Neste trabalho, lançamos mão de entrevistas realizadas com professores de Geografia que atuam na rede estadual de ensino do estado do Rio de Janeiro. Trata-se de docentes atuantes nas regiões metropolitana, serrana e Região dos Lagos. As entrevistas aqui usadas foram gravadas e transcritas. Os entrevistados assinaram o termo de consentimento livre e esclarecido e esta pesquisa foi submetida e aprovada pela Comissão de Ética de Pesquisa. Os nomes dos entrevistados são fictícios, tal como acordado.
} 


\section{Pa COC}

vista ser esta avaliação sistemática assumida como alinhamento aos conteúdos do currículo mínimo timbrados pela secretaria.

Neste movimento de aumento da precisão da proposta, também via avaliação, é possível destacar tensões entre diferentes contextos políticos. Para compreensão deste cenário de tensões, que aqui assumimos como delineado com a proposição desta política específica, utilizaremos como estratégia metodológica a abordagem ao ciclo de políticas, formulada pelo sociólogo inglês Stephen Ball. O ciclo de políticas de Ball é uma via de compreensão heurística na qual o autor identifica, em sua proposição inicial (Ball, 1992; 1994), três contextos diferentes no que diz respeito a políticas educacionais. Estes contextos estão sempre envolvidos em processos de negociação e produção de políticas, “(...) estes contextos estão interrelacionados, não tem uma dimensão temporal ou sequencial e não são etapas lineares." (MAINARDES, 2006, p.50).

Para analisar as tensões que foram estabelecidas a partir processo de difusão do currículo mínimo na rede estadual de ensino, em sua relação com as arenas políticas participantes destas políticas - secretaria de educação, coordenadorias regionais de educação, assessoria de imprensa da secretaria, unidades escolares e professores -, nos apoiaremos na abordagem do ciclo de políticas públicas de Ball para identificar as possibilidades interpretativas da política curricular no estado do Rio de Janeiro, bem como as tensões que caracterizam a produção da política. Importa destacar, em concordância com os referenciais com os quais operamos, que as leituras que aqui defendemos não podem ser assumidas como verdades em si, mas são momentos de um contexto político mais amplo que não podemos acessar. Com vistas a um maior detalhamento, focalizamos a definição do ciclo de políticas nos termos dos contextos definidos por Ball. Nesse sentido, para Mainardes:

O primeiro contexto é o contexto de influência onde normalmente as políticas públicas são iniciadas e os discursos políticos são construídos. É nesse contexto que grupos de interesse disputam para influenciar a definição das finalidades 


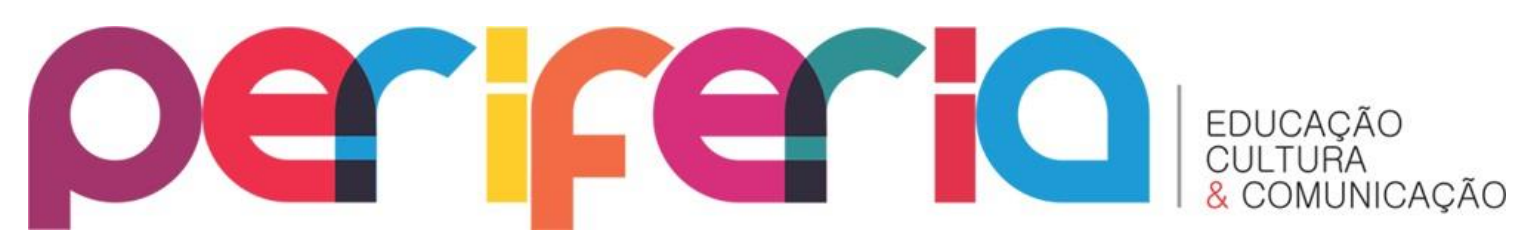

sociais da educação e do que significa ser educado. (...) 0 contexto de influência tem uma relação simbiótica, porém não evidente ou simples, com o segundo contexto, o contexto da produção de texto. Ao passo que o contexto de influência está freqüentemente relacionado com interesses mais estreitos e ideologias dogmáticas, os textos políticos normalmente estão articulados com a linguagem do interesse público mais geral. (...) De acordo com Ball e Bowe (Bowe et al., 1992), o contexto da prática é onde a política está sujeita à interpretação e recriação e onde a política produz efeitos e consequiências que podem representar mudanças e transformações significativas na política original. Para estes autores o ponto-chave é que as políticas não são simplesmente "implementadas" dentro desta arena (contexto da prática), mas estão sujeitas à interpretação e, então, a serem “recriadas". (MAINARDES, 2006)

Portanto, apropriamo-nos da perspectiva de Ball (1992) procurando entender como se deu parte dos desdobramentos envolvidos na proposição do currículo mínimo no Estado do Rio de Janeiro. Consideramos, portanto, a secretaria de educação - SEEDUC - RJ - como contexto de influência à política sob recorte neste trabalho. Pensamos a assessoria de imprensa da secretaria e as coordenadorias metropolitanas de educação, responsáveis pela elaboração e difusão dos textos, como contexto da produção de texto. Já as unidades escolares, são compreendidas como o que Ball define como contexto da prática. Ressaltamos que tais definições, em si, já consistem em violência para com formas outras e interessantes de interpretar a política em questão. Argumentamos nesse sentido por não considerarmos redutível a potência de outras identificações ou mesmo deslocamentos interpretativos ao redefinirem, em função de outras prioridades investigativas, perspectivas sobre os contextos de formas distintas.

Quando procuramos valorizar uma perspectiva docente diante desta política educacional, estamos concordando com Ball e Bowe na medida em que acreditamos que o desenvolvimento de uma política nunca se dá, de fato, sem sofrer transformações, traduções contextuais (LOPES, CUNHA e COSTA, 2013) nas mais distintas oportunidades, identificações, subjetivações na política. No nosso caso, focalizamos como tais ressignificações da política são 


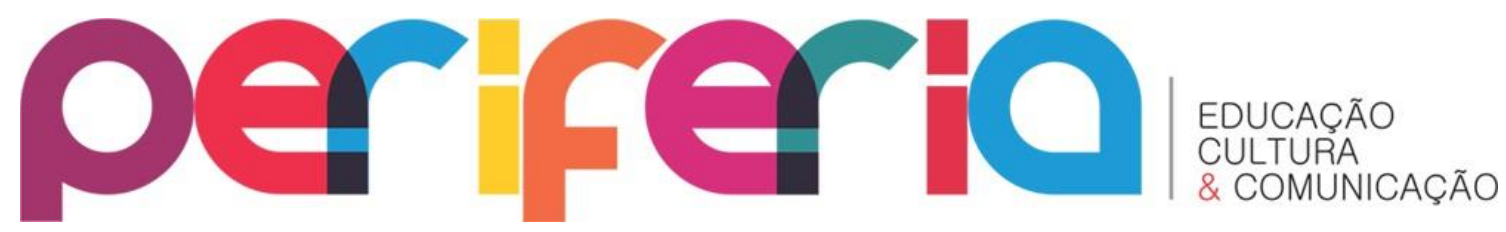

produzidas no que ponderamos como contexto da prática. Por este motivo, focalizamos as entrevistas com docentes, entendendo-os como também produtores da política, tendo em perspectiva a impossibilidade de seu fechamento, da determinação de significações últimas em qualquer contexto:

(...) os profissionais que atuam no contexto da prática [escolas, por exemplo] não enfrentam os textos políticos como leitores ingênuos, eles vêm com suas histórias, experiências, valores e propósitos (...). Políticas serão interpretadas diferentemente, uma vez que histórias, experiências, valores, propósitos e interesses são diversos. A questão é que os autores dos textos políticos não podem controlar os significados de seus textos. Partes podem ser rejeitadas, selecionadas, ignoradas, deliberadamente mal entendidas, réplicas podem ser superficiais etc. Além disso, interpretação é uma questão de disputa. Interpretações diferentes serão contestadas, uma vez que se relacionam com interesses diversos, uma ou outra interpretação predominará, embora desvios ou interpretações minoritárias possam ser importantes. (BALL et al., 1992, p. 22)

Uma vez colocados estes aspectos estratégicos e, sobretudo, a maneira como apreendemos a política educacional, atentamos ao contexto da prática. Interessa-nos, nesse sentido, compreender como os professores de geografia significam a política que envolveu a elaboração da proposta curricular e, mais especificamente, como produzem sentidos na relação com as políticas ditas oficiais em suas práticas, como negociam na proposta/política, produzindo-as simultaneamente.

Antes, contudo, de avançarmos em uma discussão sobre os sentidos de prática, consideramos interessante argumentar um tanto mais sobre 0 currículo mínimo de geografia, com vistas a pensá-lo nos termos dos hibridismos e rasuras que estruturam o texto oficial. 


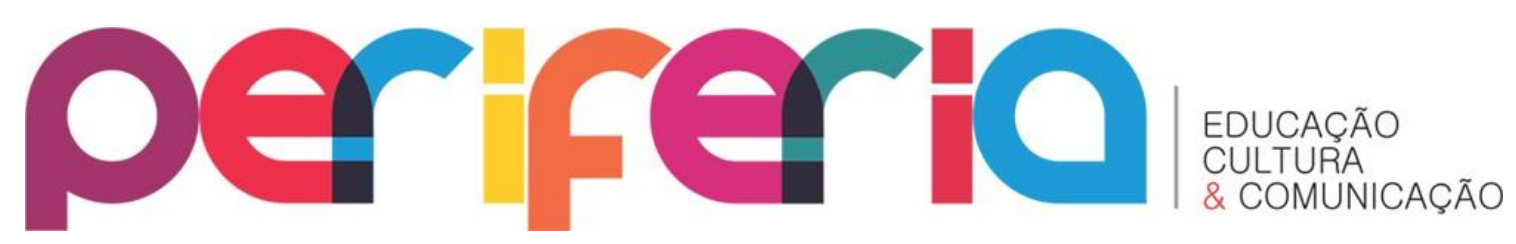

\section{O CURRÍCULO MÍNIMO PELA AVALIAÇÃO}

Como a utilização do currículo mínimo no estado do Rio de Janeiro passou a ser algo interpretado pelos docentes como normativo, uma determinação sobre a condução da prática, em razão do aumento de seu caráter restritivo, as negociações e articulações que os atores dos diferentes contextos políticos vem travando ganham contornos difíceis e as tensões se amplificam, de modo a impossibilitar culpabilizações ou leituras de homogêneas na produção política.

Apesar disso, argumentamos que a escolha dos conteúdos, coordenada em uma proposta baseada em habilidades e competências, assinala uma preocupação em instrumentalizar o conhecimento, restringindo, ao mesmo tempo, a própria ideia do que vem a ser conhecimento. Longe de propor uma definição deste, nossa inquietação passa pelo questionamento de formas de circunscrição do que pode ser ou não apropriado como conhecimento. 0 documento curricular em foco não indica métodos e tampouco caminhos no processo de ensino-aprendizagem, apenas determina os objetivos que devem ser alcançados por alunos e professores:

O currículo mínimo não define métodos, materiais didáticos ou formatos, mas sim resultados: o que o aluno deve ser capaz de fazer e saber ao final de cada ano de ensino, dentro de alguns temas, conteúdos, competências e habilidades. (Entrevista com Superintendente de Assuntos estratégicos da Seeduc-RJ, 2012).

Priorizar os objetivos sem determinar os rumos para alcançá-los. Esta estratégia encontra justificativa em um segundo, e não menos importante, compromisso com o qual a política do currículo mínimo firmou selo: as avaliações externas.

Com o cumprimento do currículo mínimo, o aluno também tem a garantia de estar sendo preparado para avaliações como a Prova Brasil e o Enem, afirmou o secretário. O currículo 


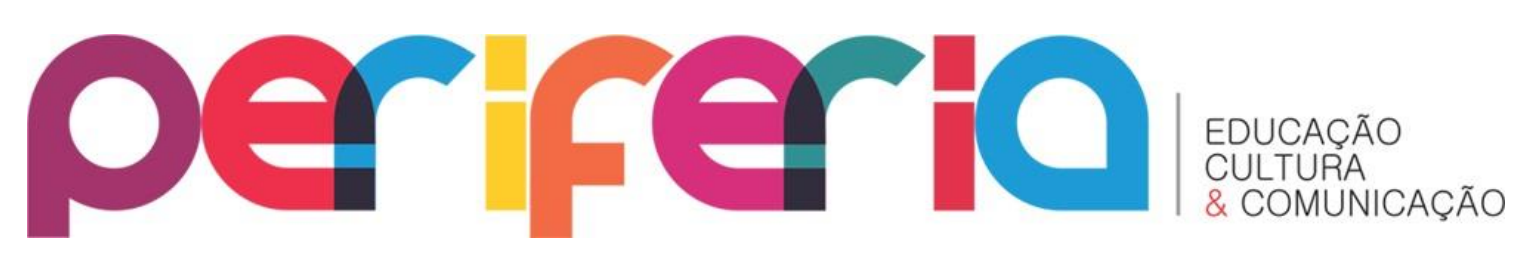

mínimo não define métodos, materiais didáticos ou formatos, mas sim resultados: o que o aluno deve ser capaz de fazer e saber ao final de cada ano de ensino, dentro de alguns temas, conteúdos, competências e habilidades. (Entrevista com Superintendente de Assuntos estratégicos da Seeduc-RJ, 2012).

Temos então, identificados dois pilares que sustentam o horizonte da proposta: homogeneização de conteúdos e avaliações externas, estando o primeiro definido a partir do segundo. Portanto, o cenário estabelecido é o de uma proposta curricular estanque e única para dar conta de mais de $\mathbf{8 8 0 . 0 0 0}$ alunos matriculados, distribuídos em cerca de 1300 escolas, num território de 43.696 Km², marcado por diferentes culturas, disparidades econômicas, áreas conurbadas de importância nacional, pequenas áreas rurais de alcance local, indústrias dos mais variados segmentos localizadas de maneira dispersa sobre o território e diversas outras demandas.

No processo de elaboração da proposta curricular, um número reduzido de professores - 7 docentes da rede - foram selecionados para colaborar com o balizamento dos conteúdos e definir quais competências e habilidades dariam o norte ao currículo mínimo.

Ao analisar o documento divulgado no ano de 2012, destacamos uma abordagem genérica, no que diz respeito aos conteúdos escolhidos e estabelecidos na proposta. Como exemplo deste caráter vago, destacamos o que é determinado para a disciplina geografia no $1^{\circ}$ bimestre do $6^{\circ}$ ano do ensino fundamental na figura 1 : 


\section{per

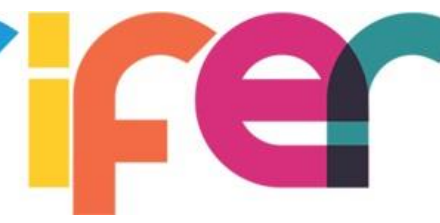

Figura 1 - Fonte: Currículo Mínimo de Geografia do $6^{\circ}$ ano do ensino fundamental

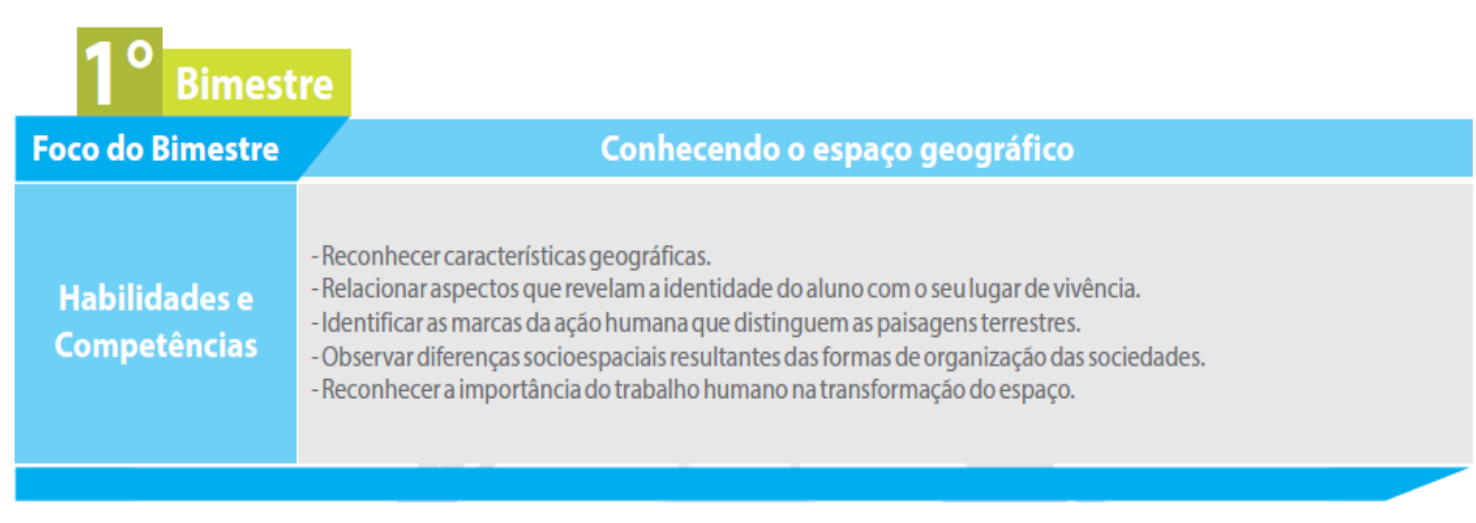

Fonte: SEEDUC-RJ, 2012.

São 5 tópicos que devem ser desenvolvidos em um bimestre, para alunos que, neste momento da vida escolar, possivelmente estão no primeiro contato com a disciplina de forma individualizada, e de início abordam conceitos e ideias caras à geografia, tais como: identidade, paisagem, transformação do espaço e lugar.

Para além da abordagem de conceitos complexos, chama a atenção o primeiro tópico proposto: Reconhecer características geográficas. Neste ponto de início, cabe a questão - Quais características? Como determinar estas características para alunos do $6^{\circ}$ ano do ensino fundamental, tendo em vista seu primeiro contato com a disciplina de forma específica? E aprofundando estas questões: as características geográficas dos diferentes espaços do Estado do Rio de Janeiro são as mesmas a serem reconhecidas ou estariam dadas? Supondo ser negativa a resposta à pergunta anterior, esta geografia de proximidade com o espaço vivido faria sentido em uma proposta que tem como objetivo conteúdos gerais para todos os alunos?

Todas estas questões aparecem como deslizamentos deste currículo mínimo, que parece tentar sincronizar demandas dispersas e, ao mesmo tempo, se respaldar numa geografia do espaço vivido, que não se sustenta teórico-metodologicamente na proposta curricular como um todo, haja vista 


\section{periferio}

defender um horizonte de padronização de conhecimentos, o que pode ser lido como incompatível com uma ressalva à experiência e/ou vivência subjetiva.

Outra secção da proposta curricular interessante a nossa argumentação é o trecho em que se tematiza sobre o continente africano. Um debate potente que é travado não só na geografia escolar, mas no campo da educação em geral (GOMES, 2003), é como tratar as questões referentes ao continente africano sem estereótipos preconceituosos e, minimamente, mostrar a existência de uma pluralidade cultural, econômica, étnica, social e tantas outras aos alunos. Não se trata de um mergulho profundo em todo espectro de discussões que o estudo do continente africano pode oferecer, mas elementos para fomentar uma visão geral acerca da África, para além do clichê racial e tematização sobre degradação econômico-social. Segue na figura 2 o que foi elaborado para $\circ 9^{\circ}$ ano do ensino fundamental para tratar do continente africano:

Figura 2 - Fonte: Currículo Mínimo de Geografia do $9^{\circ}$ ano do ensino fundamental

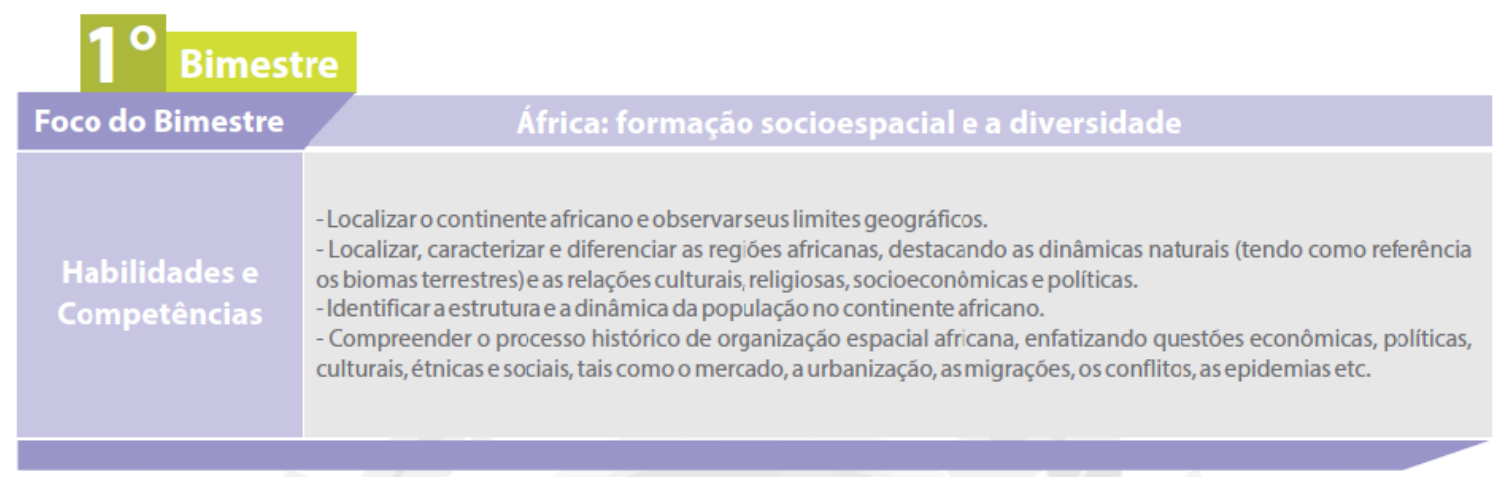

Fonte: SEEDUC-RJ, 2012.

Começando pelo foco do bimestre, o tema "África: formação socioespacial e a diversidade", o foco é desdobrado em tópicos vagos e, por conta da organização do tempo escolar que o currículo mínimo colabora a impor a questão da diversidade, seja ela qual for, fica comprometida - 


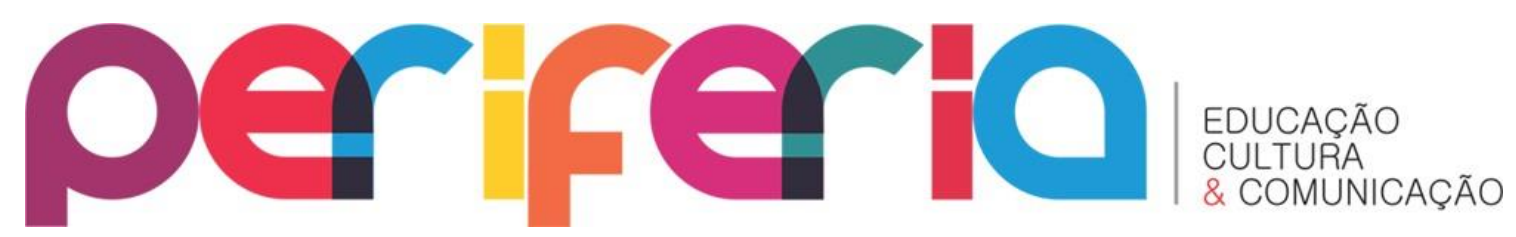

através de uma abordagem rápida e superficial. Localizar e diferenciar as regiões africanas, identificar a estrutura e a dinâmica da população africana é algo determinado e colocado de maneira central na proposta. Em detrimento desta centralidade, as questões culturais, religiosas, étnicas são posicionadas perifericamente, seja pelo escasso tempo para explorar estas questões, ou seja, pelo direcionamento que os tópicos determinados impõem.

Ao longo da proposta curricular, o tom genérico e o compromisso com uma geografia escolar preocupada em dar conta de explicar o espaço sob a lógica de um mundo estruturado em dominadores e dominados, posicionando questões culturais de maneira periférica, além de pautar uma geografia física meramente descritiva são marcas definidas.

Também tendo em vista tais elementos, passamos a destacar a visão de alguns professores da rede estadual sobre o currículo mínimo da SEEDUC - RJ, buscando pensar como tais proposições são significadas pelos docentes em suas relações com práticas e experiências.

\section{SENTIDOS DOCENTES E OS MÍNIMOS}

Como já mencionado, como parte da busca pela compreensão dos dinamismos da proposta curricular, nos utilizamos de entrevistas semiestruturadas realizadas com professores envolvidos na política em foco, atuantes em escolas públicas estaduais do estado do Rio de Janeiro, não com vistas à suposição de um acesso à verdade da política, mas como um momento produtivo das políticas de currículo: a textualização em que se constituem as perspectivas postas em circulação por professores. Com tais entrevistas, buscamos compreender as tensões projetadas pelos docentes em relação às propostas da SEEDUC-RJ, sem, com isso, negligenciar a ideia de que não há fronteiras nítidas entre as afirmações na política. Procuramos identificar, portanto, como no contexto da prática - neste caso representado pela atuação dos professores - os docentes recontextualizam conteúdos e enfoques propostos pelo currículo mínimo de geografia. 


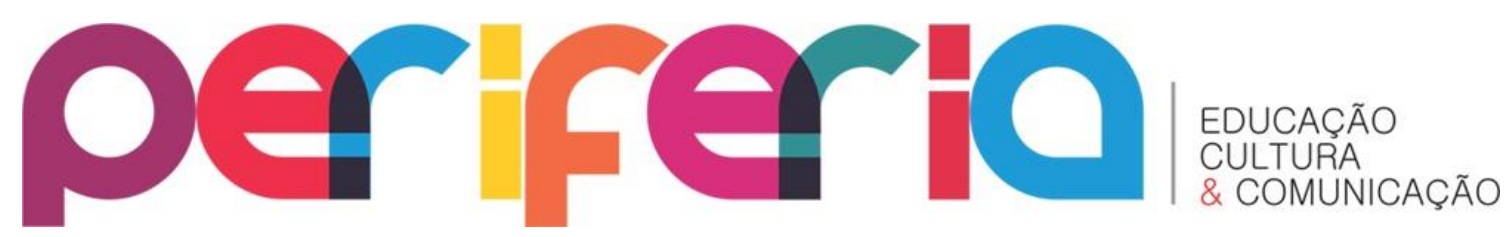

Alguns elementos comuns à fala dos professores convergem com a nossa visão acerca do documento curricular em análise no que diz respeito à forma a qual o currículo mínimo foi proposto para a rede. Mas destaca-se a interpretação do caráter verticalizado da produção política na argumentação dos entrevistados, como nos trechos a seguir:

A implantação foi vertical... por imposição. Muito embora alguns professores discordem, me incluo entre eles, a maioria adotou sem sequer discutir a medida. (Professor Thiago, Colégio Estadual Lia Márcia, SEEDUC - RJ)

Foi de cima para baixo, de um ano para o outro perdemos espaço de criar dentro do processo de ensino e tivemos nossa atividade de professor condicionada ao currículo mínimo. (Professor Daniel, Colégio Estadual Getúlio Vargas)

A superficialidade na abordagem dos conteúdos é motivo de preocupação por parte dos docentes, além do distanciamento das propostas contidas no currículo mínimo em relação ao aluno. Este afastamento entre produção curricular e a vivência do aluno, na opinião dos professores entrevistados, é causado pelo alinhamento que esta proposta de currículo tem com as avaliações externas.

0 negativo fica por conta da abordagem superficial, do reduzido quantitativo de conteúdos quando comparado a qualquer escola particular, mesmo as que comprovadamente não apresentam grande qualidade e, sobretudo, a tentativa de introduzir avaliações externas que por vezes são descoladas da realidade do alunado. (Professor Thiago, Colégio Estadual Lia Márcia, SEEDUC-RJ)

o currículo mínimo estabelecido pelo estado requer um aprofundamento principalmente nos anos iniciais do ensino fundamental II, além de não estar relacionado com o mundo do aluno (Professora Marcela, Centro Integrado de Educação Pública Hilda do Carmo Siqueira, SEEDUC-RJ)

Se por uma lado a crítica ao controle por parte da secretaria, através da definição de conteúdos mínimos é um ponto de crítica docente, por outro 


\section{Pa CPC}

também há sentidos de defesa ao aumento na definição do rol de conteúdos, o que seria díspar, também, quando de uma perspectiva de produção de conhecimento geográfico atado à realidade do aluno. Desta forma, uma questão a ser projetada seria: um eventual aumento na proposição de conteúdos poderia assegurar maior contato com as demandas e experiências daquilo que dizemos ser uma realidade do aluno? Argumentamos que, apesar da crítica ao caráter verticalizado e controlador da proposta, o sentido de controle também pode ser lido nas falas docentes, tanto em relação ao conhecimento e sua produção, como em relação à própria necessidade de elaboração de documentos mais detalhados, mais precisos.

Outra questão que se destaca é a das avaliações externas. Um ponto comum à fala dos docentes é que estas avaliações reduzem o processo de ensino-aprendizagem à preparação do aluno para realizar as avaliações externas, já que estas são importantes instrumentos de avaliação de rede como um todo. Ao serem questionados sobre como a secretaria e as coordenadorias metropolitanas exercem algum tipo pressão sobre os professores em relação ao cumprimento do currículo mínimo, a questão das avaliações externas aparece com destaque:

Não vejo problema em amarrar conteúdos à avaliações externas, desde que essas avaliações se aproximem minimamente da realidade do alunado e do currículo proposto, o que não é o caso do Saerj ${ }^{6}$ e da Seeduc, respectivamente. 0 que percebemos é uma busca incessante pela produção de números, indicadores, que melhorem o resultado da educação do estado e sirvam de plataforma eleitoral, mesmo que maquiados por programas como o autonomia e o mais recente CF (Correção de Fluxo) a ser implantado em 2015. Não sou contra avaliações em escala macro, mas ao modo como são impostas e a utilidade que elas tem para os gestores da educação do estado não me agradam, e tampouco acredito que contribuam para a educação estadual. (Professor Thiago, Colégio Estadual Lia Márcia, SEEDUC-RJ)

\footnotetext{
${ }^{6}$ Sistema de Avaliação do Estado do Rio de Janeiro.
} 


\section{periferio}

A pressão por resultados é muito grande, principalmente nas avaliações externas, que são simplesmente compatíveis com o currículo mínimo, mas exigem estudo e comprometimento do aluno, que muitas vezes não apresenta (Professora Marcela, Centro Integrado de Ensino Público Hilda do Carmo Siqueira, SEEDUC-RJ)

Sobre a releitura do currículo, ou como os docentes recontextualizam este, a superficialidade do tratamento temático, entre as falas docentes, é recorrente, por outro a pressão por resultados nas avaliações externas é algo que tende a condicionar possibilidades de escape dos professores de geografia a novas possibilidades. Ainda assim, é possível identificar perspectivas lidas como autonomia ou mesmo emancipação na atuação profissional:

"Procuro explorar o conceitos ligados a relação entre de sociedade e natureza e relações internacionais." (Professora Marcela, Centro Integrado de Ensino Público Hilda do Carmo Siqueira, SEEDUC-RJ)

"Tento aproximar, principalmente nas turmas de $6^{\circ}$ ano, uma série de conceitos da geografia que são mal posicionados no currículo mínimo ao espaço de vivência do alunado." (Professor Daniel, Colégio Estadual Getúlio Vargas)

\section{CONSIDERAÇÕES FINAIS}

A definição do texto curricular proposto pela SEEDUC - RJ é criticada pelos docentes em razão de ter ocorrido com consultas limitadas a professores da rede de educação, sem a promoção de debates mais amplos. Em função de tal leitura, é recorrente a perspectiva de que houve um aumento na pressão de trabalho dos professores, através da imposição das avaliações externas de macro-escala. No caso da rede estadual de ensino do Rio de Janeiro, as avaliações que eram apenas diagnósticas ao longo do tempo passaram a compor a nota bimestral do aluno. Como o conteúdo cobrado nestas avaliações está exclusivamente alinhado com a proposta de currículo mínimo e, um dos principais medidores de qualidade de ensino utilizados pelo governo 


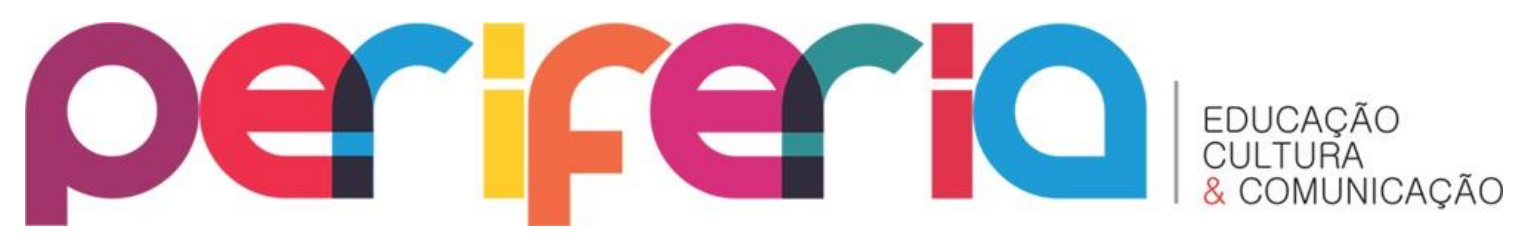

estadual é gerado via desempenho dos alunos nas avaliações centrais, é possível fazer a seguinte leitura: A visão de imposição da proposta curricular da rede estadual, por parte dos docentes, se organiza em torno da leitura de que a secretaria atuou de forma verticalizada e a implementação da proposta se deu numa escalada de tensões, uma vez que partiu de uma elaboração sem abertura para a participação democrática e o seu controle vem sendo garantido através de avaliações externas de macro-escala.

Portanto, imposição e controle do currículo são marcas, segundo os docentes, da gestão da educação da SEEDUC - RJ. Sendo assim, a Secretaria é pensada como se apoiando em uma concepção de currículo que reitera a organização temporal de conteúdos e, por conta de uma excessiva valorização de avaliações externas, os espaços para outras demandas, sobretudo, de escalas locais, culturais - do contexto da prática - são pressionados e, muitas vezes, assinalando seu caráter acessório ou marginal, em razão de não serem compreendidos na avaliação.

Contudo, ainda neste cenário em que as macro-esferas de poder político (representadas aqui pela secretaria de educação e seus órgãos auxiliares) são lidas como dinâmicas controladoras da prática docente, também destacamos que as reinterpretações docentes, no contexto da prática, produzem sentidos que também podem ser compreendidos como borrados entre entre si, possibilitando perspectivas que tendem não só a apoiar enfoques que julgam caracterizar as práticas violentas do orgão gestor, como a aprofundar movimentos de controle. Nossa ressalva acena para defesas docentes que apontam uma maior precisão da proposta em termos de conteúdos, passando por aqueles que negociam com o documento oficial diferentes formas de abordagem aos conteúdos (criticando sua orientação, propondo diferentes formas de discussão sem abandonar os temas centrais da proposta), até aqueles que defendem uma visão capaz de dar conta de todas as demandas do alunado.

É possível perceber, na fala dos professores, que a insatisfação dos docentes frente ao currículo da rede consiste na visão de descontentamento e 


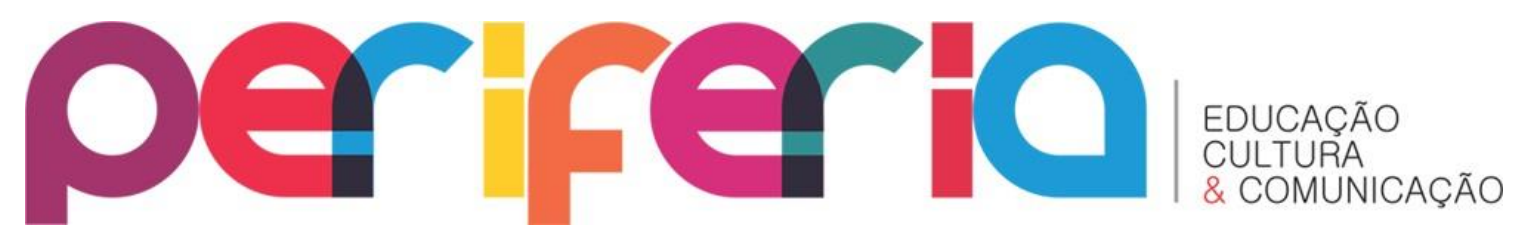

proposição de alterações no documento. Entretanto, uma consideração final deste texto é que a perspectiva de política dos professores eufemiza sua atuação como produtores de sentidos para as políticas. Argumentamos que se com Ball é possível compreender a política como produzida continuamente, não cabe restringir sua leitura aos fazeres da secretaria e órgãos adjuntos, mas a todo um conjunto de envolvimentos de gestores, secretários, professores, alunos, bem como de todo um contexto social mais amplo. Ao atentar às demandas colocadas pelos professores também não as assumimos como verdades últimas da política, sobre a política, mas colocamos que da crítica a determinados trechos do documento oficial, em sua imprecisão sobre o tratamento de temas, até as oposições colocadas pelos docentes, temos um pequeno trecho da amplitude da política. Uma política produzida por todos os envolvidos, contaminada por todos, feitas de iterações textuais incessantes. Oposições, contradições, irrupções, foraclusões, assim como toda forma de agir na relação com o ensino de geografia, com a educação em geral, não deixam de ser sintomas de um fazer político que extrapola nosso escopo de análise, desdobrando-se nos mais diferentes espaços-tempos cotidianos escolares.

Consideramos que uma posição interessante a este trabalho, no qual buscamos entrelaçar sentidos dos documentos oficiais e das falas de professores com os aportes teóricos de Ball, é conceber a produção política como disseminada em toda forma de envolvimento com ela. Com isso, não estamos reduzindo a possibilidade de as hegemonias operarem de forma a tentar fechar o significado da própria política, da educação, do currículo, do ensino de geografia. Ao contrário, queremos enfatizar que toda forma de decisão na política é marcada por um movimento pró-hegemônico, no qual todos os atores imbricados no processo, nas articulações, produzem sentidos que visam à universalidade.

Desse modo, secretarias, gestores, pais, alunos, docentes e pesquisadores, operam ativamente a produção da política curricular, detonando, contextualmente, movimentos hegemônicos a partir daquilo que, 


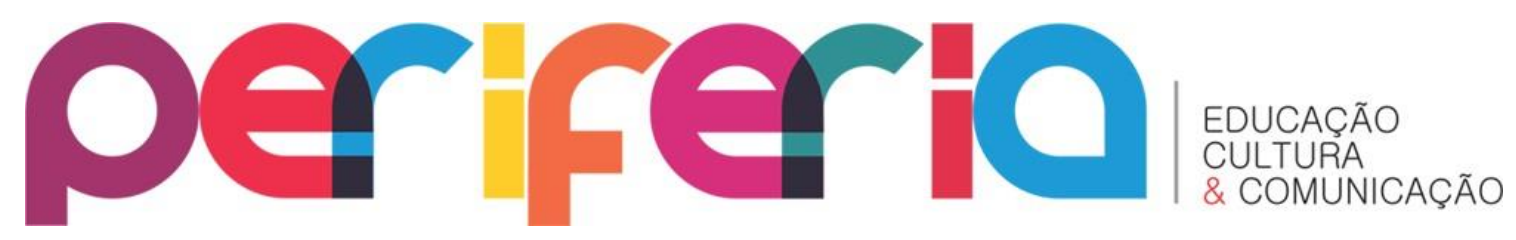

nestes mesmos contextos, julgam como importante a ser defendido como horizonte. O caráter rasurado da política, marcado também por legíveis contradições, como quando eventualmente encontramos uma professora ou professor defendendo leituras aparentemente mais precisas de controle curricular, não pode perder de vista que, ainda que possam ser criticáveis, as perspectivas de prática que o docente constitui na relação com aquilo que tem por desafio em sua experiência profissional, o possibilita a ler como melhoramento ou oportunidade aos alunos, à carreira, à dinamização de determinado fim. Os envolvimentos, as rasuras, as aparentes contradições e incompatibilizações reiteram, a nosso ver, o caráter (de)generativo da produção política, haja vista seu não-fechamento, sua inconclusão, sua volatilidade a si, sua precariedade na relação com toda forma ultima de fechar o acesso. Esta noção nos possibilita a sensação de que é possível afirmar que vias de controle curricular estão por toda parte, ao tempo que toda forma de combate a ele também é também pretender controlar algo. Professores nos mais distintos espaços de poder em que atuam, portanto, visando concordar ou discordar daquilo com que julgam defrontar na política oficial, sempre traduzem de formas rasurantes, porque já noutro contexto, em uma experiência conflituosa singular.

\section{REFERÊNCIAS}

BALL, Stephen J.; MAINARDES, Jefferson (orgs). Políticas Educacionais: Questões e Dilemas. São Paulo: Cortez, 2011.

BALL, Stephen J. Education Reform: A critical and post-estructural approach. Buckinghan: Open Universit, 1994.

BALL, Stephen J. The policy processes and the processes of policy. In: Bowe, R.; Ball, S. \& Gold, A. Reforming education \& changing school: case studies in policy sociology. Londres - Nova lorque: Routlegde, 1992.

GOMES, Nilma Lino. Cultura negra e educação. São Paulo: Revista Brasileira de Educação, 2003, n.23, p. 75-85. 


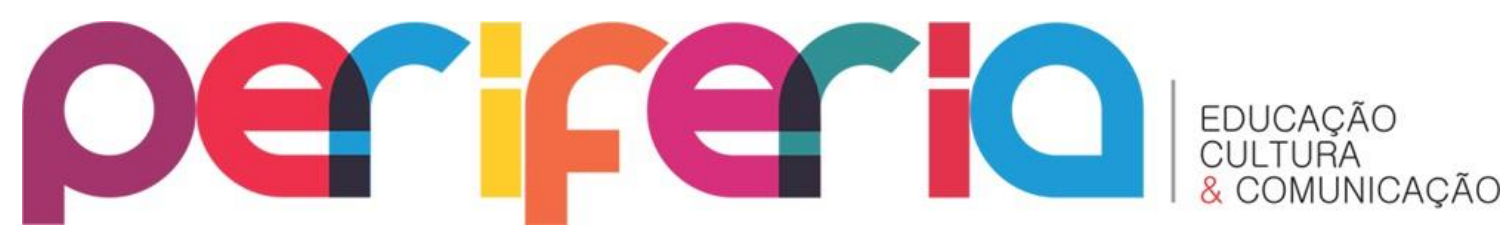

ENTREVISTA DO SUPERINTENDENTE de assuntos estratégicos da Seeduc-RJ Mario Godoy. Disponível em www.rj.gov.br/seplag. Acesso em 15/09/2015.

FOUCAULT, Michel. Microfísica do poder. Rio de Janeiro: Graal, 2012.

LOPES, Alice Casimiro; CUNHA, E. ; COSTA, H. H. C. Da recontextualização à tradução: investigando políticas de currículo. Rio de Janeiro: Currículo sem Fronteiras, 2013, v. 13, p. 392-410.

MAINARDES, Jefferson. Abordagem do ciclo de políticas: Uma contribuição para a análise de políticas educacionais. Campinas: Educação e Sociedade, v.27, n.94, p.47-49, jan/abr, 2006.

RIO DE JANEIRO (Estado). Secretaria de Estado de Educação do Rio de Janeiro - SEEDUC - RJ. Currículo mínimo 2013. Rio de Janeiro, 2012.

RIO DE JANEIRO (Estado). Portaria SEEDUC/SUGEN n. 419 de 27 de setembro de 2013. Estabelece normas de avaliação do desempenho escolar e dá outras providências. Diário Oficial do Estado do Rio de Janeiro, Poder Executivo 30 de setembro de 2013. 